\title{
Isolation and characterization of novel microsatellite markers and their application for diversity assessment in cultivated groundnut (Arachis hypogaea)
}

\author{
Luu M Cuc ${ }^{1,2}$, Emma S Mace ${ }^{1,3}$, Jonathan H Crouch ${ }^{1,4}$, Vu D Quang2, \\ Tran D Long 5 and Rajeev K Varshney*1
}

Address: ${ }^{1}$ International Crop Research Institute for the Semi Arid Tropics (ICRISAT), Patancheru- 502 324, Greater Hyderabad, Andhra Pradesh, India, ${ }^{2}$ Agriculture Genetics Institute, Vietnamese Academy Agriculture Science, Van Dien, Thanh Tri, Hanoi, Vietnam, ${ }^{3}$ Department of Primary Industries \& Fisheries, Hermitage Research Station, 604 Yangan Road, Warwick, QLD 4370, Australia, ${ }^{4}$ International Wheat and Maize Improvement Centre (CIMMYT), Apdo. Postal 6-641, 06600 Mexico, D.F., Mexico and 5Vietnamese Academy Agriculture Science, Van Dien, Thanh Tri, Ha Noi, Vietnam

Email: Luu M Cuc - cucchi04@gmail.com; Emma S Mace - Emma.Mace@dpi.qld.gov.au; Jonathan H Crouch - j.crouch@cgiar.org; Vu D Quang - vdquanghn@gmail.com; Tran D Long - long_trandinh@yahoo.com; Rajeev K Varshney* - r.k.varshney@cgiar.org

* Corresponding author

Published: 15 May 2008

BMC Plant Biology 2008, 8:55 doi:1 0.1 I86/I47|-2229-8-55
Received: 22 February 2008

Accepted: 15 May 2008

This article is available from: http://www.biomedcentral.com/I47/-2229/8/55

(c) 2008 Cuc et al; licensee BioMed Central Ltd.

This is an Open Access article distributed under the terms of the Creative Commons Attribution License (http://creativecommons.org/licenses/by/2.0), which permits unrestricted use, distribution, and reproduction in any medium, provided the original work is properly cited.

\begin{abstract}
Background: Cultivated peanut or groundnut (Arachis hypogaea L.) is the fourth most important oilseed crop in the world, grown mainly in tropical, subtropical and warm temperate climates. Due to its origin through a single and recent polyploidization event, followed by successive selection during breeding efforts, cultivated groundnut has a limited genetic background. In such species, microsatellite or simple sequence repeat (SSR) markers are very informative and useful for breeding applications. The low level of polymorphism in cultivated germplasm, however, warrants a need of larger number of polymorphic microsatellite markers for cultivated groundnut.

Results: A microsatellite-enriched library was constructed from the genotype TMV2. Sequencing of 720 putative SSR-positive clones from a total of 3,072 provided 490 SSRs. $71.2 \%$ of these SSRs were perfect type, $13.1 \%$ were imperfect and $15.7 \%$ were compound. Among these SSRs, the GT/CA repeat motifs were the most common (37.6\%) followed by GA/CT repeat motifs $(25.9 \%)$. The primer pairs could be designed for a total of 170 SSRs and were optimized initially on two genotypes. $104(61.2 \%)$ primer pairs yielded scorable amplicon and 46 (44.2\%) primers showed polymorphism among 32 cultivated groundnut genotypes. The polymorphic SSR markers detected 2 to 5 alleles with an average of 2.44 per locus. The polymorphic information content (PIC) value for these markers varied from 0.12 to 0.75 with an average of 0.46 . Based on $1 / 2$ alleles obtained by 46 markers, a phenogram was constructed to understand the relationships among the 32 genotypes. Majority of the genotypes representing subspecies hypogaea were grouped together in one cluster, while the genotypes belonging to subspecies fastigiata were grouped mainly under two clusters.

Conclusion: Newly developed set of 104 markers extends the repertoire of SSR markers for cultivated groundnut. These markers showed a good level of PIC value in cultivated germplasm and therefore would be very useful for germplasm analysis, linkage mapping, diversity studies and phylogenetic relationships in cultivated groundnut as well as related Arachis species.
\end{abstract}




\section{Background}

The cultivated peanut or groundnut, Arachis hypogaea L., $(2 \mathrm{n}=4 x=40)$ is a major crop in most tropical and subtropical areas of the world, with $68 \%$ of groundnut cultivated world-wide produced in Asia (23 Mt), 24\% in Africa $(8 \mathrm{Mt})$ and the remaining $8 \%(3.5 \mathrm{Mt})$ from North America, the Caribbean, Europe and Oceania [1]. The seeds are used for direct human consumption, and as an oil and protein source [2]. Additionally, plant residues are extremely important as fodder for cattle in many regions of the world [3]. The crop is becoming increasingly important as an income source in tree plantations before tree crops mature. In Africa and Asia, groundnut is intercropped between maize, sorghum, and soybean or, in a few areas, between mature coconut trees [4].

In contrast to the wealth of phenotypic diversity observed within cultivated groundnut, the genetic diversity observed to date within the cultivated gene-pool is much lower. This low level of genetic variation in cultivated groundnut is attributed to its origin from a single polyploidization event that occurred relatively recently on an evolutionary time scale [5]. However, additional contributing factors to the low levels of molecular polymorphism observed to date could be the marker techniques used and the amount of diversity of samples tested [6].

Molecular markers, in general, and microsatellites or simple sequence repeats (SSRs) in particular have proven very useful for crop improvement in many species [7]. In groundnut, the use of molecular markers for breeding applications, however, has been limited by the low level of the genetic variation in this species. Nevertheless, in recent years, significant efforts have been made to develop the SSR markers in groundnut [8-10]. Development of SSR markers traditionally requires cloning and sequencing and hence is more cost and labour-intensive, compared to PCR arbitrary priming techniques e.g. randomly amplified polymorphic DNAs (RAPDs), amplified fragment length polymorphism (AFLP) [7]. However, once the SSR markers are developed, their applications in breeding activities particularly using high throughput approaches becomes very cost effective. To isolate the SSRs from genomic DNA libraries, several approaches for creating SSR-enriched genomic libraries have been developed, with SSR selection either before [11-13] or after genomic library construction [14].

By using different approaches, > 500 SSRs have been developed in groundnut [15]. By using these SSR markers, good progress has been made in developing the genetic maps and diversity studies in AA- and BB-genome groundnut species $[8,9,16-22]$. In case of cultivated germplasm, however, these SSR markers showed very low level of polymorphism [8,19-22]. This is one of the reasons that despite the availability of moderate number of SSR markers in groundnut, not a single genetic map based on cultivated germplasm has been published so far. To overcome the low level of polymorphism, one of simple solutions will be to develop a critical number of SSR markers in groundnut so that a repertoire of about 200-300 polymorphic SSR markers for cultivated groundnut germplasm may be available.

The present study was initiated in order to isolate and characterize new microsatellite markers from groundnut, following a microsatellite enriched genomic library approach. The overall aim of this study is to enhance the repertoire of polymorphic SSR markers for cultivated groundnut germplasm so that genetic mapping and trait mapping could be feasible in cultivated groundnut.

\section{Results and Discussion SSR-enriched library}

The SSR enriched library was constructed from the genotype TMV2 following by modified method of Fischer and Bachmann [23]. This library was enriched for CA and CT SSR repeat motifs. From this library, 3,072 clones were picked from 32 96-well plates. Hybridization of these clones with digoxigenin-labeled SSR probes (CA and CT) provided $720(23.4 \%)$ putatively positive clones. Sequencing of these clones indicated the insert size in the range of $50 \mathrm{bp}$ to $792 \mathrm{bp}$ with an average size of $309 \mathrm{bp}$. Majority of clones (43.9\%) contained the insert of moderate size (200 bp-400 bp) while $34.6 \%$ clones contained small inserts (50 bp-200 bp) and $21.5 \%$ clones contained inserts of $>500 \mathrm{bp}$.

Analysis of sequence data mentioned above with Tandem Repeat Finder (TRF) had 490 (68\%) clones which contained one or more SSRs. The efficiency of the enrichment procedure for the constructed library was higher as compared to other SSR isolation studies of groundnut. Like the present study, $61 \%$ of clones were found to contain SSRs in the study of He and colleagues [20], 56\% clones had SSRs in the study of Gimenes and colleagues [18] and $43.7 \%$ clones were reported to contain SSRs by Wang and colleagues [24]. However very low enrichment efficiency ( $10 \%$ to $31 \%$ ) were obtained in some other libraries enriched for SSRs $[8,9,21]$. Indeed, this enrichment efficiency depends on many factors including the choice of restriction enzyme used for library construction, the SSR probes used for enrichment, etc. The approach used in the present study seems to be the most efficient enrichment strategy for SSR isolation in groundnut.

A redundancy level of $26 \%$ in the SSR-enriched genomic library was observed through multiple sequence alignment analysis using the ClustalW programme; in total 5 copies of one clone was observed, 4 copies of five clones, 
3 copies of 10 clones and 2 copies of 65 clones. The rate of redundant SSR-containing clones was found to be comparable $(26 \%)$ to other studies utilizing microsatelliteenriched genomic libraries in other plant species, e.g., olive tree (Olea europaea L., 16.6\%) [25], onion (Allium cepa L. 24.3\%) [23]. As compared to SSR isolation studies in groundnut where upto $67 \%$ redundancy has been observed $[8,20,21]$, the strategy employed in the present study seems to be quite effective to isolate a higher proportion of novel and unique SSRs. Observed level of redundancy in this study could be explained due to the existence of multiple copies of some SSRs in the groundnut genome, which may be present on both the A and $\mathrm{B}$ genomes within cultivated A. hypogaea. The bias observed for some SSRs being repeated in multiple clones could also be explained by the fact that during the enrichment procedure (adaptor ligation, amplification of singlestrand enriched DNA, bacterial growth before plating) some fragments can be arbitrarily selected over the rest.

Despite the addition of excess adapter during the enrichment procedures, $7.2 \%$ of clones were identified as concatenates, generated during the initial restriction/ligation step, by the presence of internal RsaI and MluI restriction sites. Another type of concatenation may be formed during the PCR step of the enrichment cloning procedure [27]. Such chimeras usually remain undetected and may result in the failure of some primer pairs to amplify genomic DNA templates in the evaluation of primers [28].

\section{Occurrence and features of SSRs}

Sequence analysis of 720 clones showed the presence of one or more SSRs in $490(68 \%)$ clones. Following the definitions of Weber [29], 71.2\% of the SSRs identified were perfect, $13.1 \%$ were imperfect (when SSRs are interrupted by few bases) and $15.7 \%$ were compound (when more than one SSRs are spaced by few base pairs) with $9.8 \%$ being compound perfect and $5.9 \%$ being compound imperfect. Similar kind of distribution of different SSR classes was observed in different SSR isolation studies in groundnut $[8,9,18]$.

In terms of the repeat motifs, the GT/CA repeat motif was the most common, accounting for $37.6 \%$ of all repeat types, followed by GA/CT repeat at $25.9 \%$. The previous surveys carried out on microsatellite abundance in plant genomes have shown AT as the most frequently occurring dinucleotide repeat motifs followed by AG/CT and GT/CA [30-34]. The AT repeat is self-complementary and is difficult to screen for by colony hybridization, hence the library was not enriched for AT. Abundance of GA/CT, GT/CA, AT and ATT repeat motifs in isolated SSRs in groundnut in the present study is in agreement with earlier reports on isolation of SSRs in groundnut $[8,9,20,24]$. The use of separate GA and GT filters could increase the ability of detecting perfect GA/CT and GT/CA repeat motifs or the frequency of the repeats, in comparison to using mixtures of different repeat motifs in the same hybridization. However several studies have shown the retrieval of higher proportion of compound SSRs (upto $75 \%$ ) when the library was enriched using a mixture of different SSR oligos $[18,35,36]$.

The maximum repeat unit number of dinucleotide repeat motifs of GT/CA and GA/CT were 48 and 50 units, respectively; the overall repeat motif number ranging from 7 to 50. In fact, in some studies, the markers developed for longer repeat motifs were found more informative for detection of polymorphism in cultivated groundnut germplasm [9]. In addition to GT and GA repeats containing SSRs, several SSRs containing the repeat motifs$(\text { AAG })_{\mathrm{n}^{\prime}}(\mathrm{CAA})_{\mathrm{n}^{\prime}}(\mathrm{TAA})_{\mathrm{n}^{\prime}}(\mathrm{TTG})_{\mathrm{n}^{\prime}}(\mathrm{GTT})_{\mathrm{n}^{\prime}}(\mathrm{TTC})_{\mathrm{n}^{\prime}}(\mathrm{CCT})_{\mathrm{n}^{\prime}}$ $(\text { AAAG })_{\mathrm{n}^{\prime}}(\text { TTTC })_{\mathrm{n}^{\prime}}(\text { TTCTC })_{\mathrm{n}^{\prime}}(\text { CTTTT })_{\mathrm{n}^{\prime}}(\text { CTCTTT })_{\mathrm{n}}$ and (GTGTTT) $)_{\mathrm{n}}$ with 2-11 repeat numbers were also isolated. It was interesting to note that most of the clones containing these repeats had an additional repeat of GT/CA or GA/CT. Gimenes and colleagues [18] also observed 37\% SSRs with different repeats, like in the present study, that were not totally complementary sequences to the oligonucelotide probes used. However, the repeat motif ATT is highly abundant and informative in several legume species like soybean [37], chickpea [38] and pea [39] was not observed abundant in the present study. In case of groundnut, many reports are available on isolation and distribution of SSRs, only two studies $[8,9]$ indicated the abundance of AAT repeat motifs. In the present study, as only 720 clones sequenced were selected randomly from the set of 3072 clones, probably sequencing of larger number of clones could have showed the abundance of AAT repeat motifs.

\section{Marker development}

SSR containing sequences were used for primer designing using Primer3 programme. Following the standard criteria: primer length- $18-27 \mathrm{bp}$; $\mathrm{Tm}-57-63^{\circ} \mathrm{C}$; GC content - 40-60\%, maximum Tm difference between forward and reverse primer $-1.5^{\circ} \mathrm{C}$, primer pairs were designed for 170 SSR containing clones [see Additional file 1]. Of this set, $47.1 \%$ primer pairs were designed for perfect repeats, $18.2 \%$ for imperfect repeats while the remaining 34.7\% for compound repeats. For the remaining sequences, the primer designing could not be possible as in some cases sequence quality was poor while in some cases the SSRs were too near the start or end of the insert. The percentage of primers designed, in relation to the number of clones sequenced $(23.6 \%)$ is higher than some studies in groundnut like Moretzsohn and colleagues [9] (10.5\%), He and colleagues [20] (14.0\%) and Ferguson and colleagues [8] (21.3\%) while lower than some other reports such as Moretzsohn and colleagues [21] (41.4\%) and 
Wang and colleagues [24] (43.7\%). This may be attributed to the size range of insert, the restriction enzyme used for genomic DNA library construction and the approach used for SSR enrichment, etc. [7].

Newly designed SSR markers were tested for amplification on two genotypes i.e. TMV2 and ICG 99001. Of this set, only 104 (61.2\%) primer pairs yielded the scorable amplicon in the genotypes examined (Table 1). The functionality of the primer pairs is comparatively lower than the studies of Ferguson and colleagues [8] and Moretzsohn and colleagues [9] who observed amplification in $84.9 \%$ and $81.6 \%$ cases, respectively. It is noteworthy that several PCR profiles and PCR optimization strategies were adopted in above mentioned studies, however in the present study to save costs and time, PCR conditions for non-amplifiable markers were not optimized repeatedly. Out of 104 working primers, 89 (85.6\%) primer pairs were optimized on $65^{\circ} \mathrm{C}-60^{\circ} \mathrm{C}$ touch down profile, 14 (13.5\%) primer pairs optimized on $60^{\circ} \mathrm{C}-55^{\circ} \mathrm{C}$ touch down profile while only one $(0.9 \%)$ primer pair was optimized on $55^{\circ} \mathrm{C}-45^{\circ} \mathrm{C}$ specific profiles. It is quite likely to increase the rate of functionality of newly developed markers by using different PCR conditions and profiles.

It is also noted that the markers for less than 20 repeat units produced amplicons in about $73 \%$ cases, while the markers containing the higher number of repeat units (> 20 ) yielded amplicon in $16.7 \%-54.5 \%$ cases only. It is possible that higher number of repeat units make the Taq polymerase unstable that makes it unable to extend alongwith the template DNA [7].

\section{SSR polymorphism}

In order to assess the potential of newly developed SSR marker for detecting the polymorphism in $4 \times$ groundnut genotypes, all the 104 primer pairs yielding PCR products were tested on the set of 32 genotypes (Table 2). As a result, only $46(44.2 \%)$ markers showed polymorphism in the germplasm analyzed (Table 3). Of the 46 primers, 30 primers were for perfect SSRs while 16 primers were for imperfect SSRs. Marker polymorphism observed in the present study is higher or comparable to earlier studies on SSR diversity in cultivated groundnut germplasm. For example, in two different studies, He and colleagues observed polymorphism with 29.2\% [40] and 33.9\% markers [20] while $35.8 \%$ markers showed polymorphism in the study of Moretzsohn and colleagues [9]. In all these studies, the SSR markers, like in the present study, were isolated from the genomic DNA libraries. It seems that either the SSR markers developed in the present study are more informative or the germplasm surveyed here is more diverse. Higher informativeness of the newly developed markers is supported by the general theory that degree of polymorphism of the SSR marker increases with the total length of the repeat $[7,9,29]$. The majority of the markers (> 80\%) developed here contained more than 10 repeat units for the corresponding SSRs (Table 1). However, Ferguson and colleagues [8] observed higher (48.7\%) marker polymorphism as compared to this study which can be attributed to the diverse nature of the germplasm examined in their study.

In recent years, SSR markers have been developed from the expressed sequence tags (ESTs) because of increasing the emphasis on developing the functional molecular markers [10]. Luo and colleagues [22] had 20\% of the markers showing polymorphisms; while Moretzsohn and colleagues [9] detected polymorphisms in cultivated germplasm with $7.5 \%$ of the markers. Lower level of polymorphism of EST-based SSR markers can be attributed to their origin from highly conserved proportion of the genome [41]. In our opinion, the crops like groundnut having narrow genetic background needs higher number of SSR markers derived from genomic DNA library instead from cDNA library or ESTs.

The numbers of alleles detected by the set of 46 polymorphic markers were in the range of 2 to 5 with an average of 2.44 alleles per locus (Table 3 ). The PIC value for these polymorphic markers varied from 0.12 (IPAHM 92) 0.75 (IPAHM 123) with an average of 0.46 (Table 3 ).

Table I: Overview on SSR marker development and polymorphism

\begin{tabular}{llll}
\hline Repeat unit classes & Markers designed & Marker yielding amplification & Markers showing polymorphism \\
\hline $5-10$ & 15 & $11(73.3 \%)$ & $3(27.3 \%)$ \\
$11-15$ & 37 & $27(72.9 \%)$ & $14(51.8 \%)$ \\
$16-20$ & 56 & $38(73.2 \%)$ & $23(56.1 \%)$ \\
$21-25$ & 33 & $16(48.5 \%)$ & $4(25.0 \%)$ \\
$26-30$ & 11 & $6(54.5 \%)$ & $1(16.7 \%)$ \\
$31-35$ & 7 & $3(42.9 \%)$ & $1(33.3 \%)$ \\
$36-40$ & 5 & $2(40.0 \%)$ & 0 \\
$>40$ & 6 & $1(16.7 \%)$ & 0 \\
\hline Total & 170 & $104(61.2 \%)$ & $46(44.2 \%)$ \\
\hline
\end{tabular}


Table 2: Details on germplasm used for diversity analysis

\begin{tabular}{|c|c|c|c|c|}
\hline S.No. & Genotype & Botanical Variety & Country of origin & Market type \\
\hline I & ICG 4389 & hypogaea & India & virginia, runner or bunch \\
\hline 2 & ICG 10362 & hypogaea & Nigeria & virginia, runner or bunch \\
\hline 3 & ICG I097I & hypogaea & Peru & virginia, runner or bunch \\
\hline 4 & ICG I2235 & hypogaea & Bolivia & virginia, runner or bunch \\
\hline 5 & ICG I262I & hypogaea & India & virginia, runner or bunch \\
\hline 6 & ICG I3420 & hypogaea & Chad & virginia, runner or bunch \\
\hline 7 & ICGV 99003 & hypogaea & India & virginia bunch \\
\hline 8 & ICGV 99005 & hypogaea & India & virginia bunch \\
\hline 9 & ICG I5405 & hirsuta & Peru & peruvian runner \\
\hline 10 & ICG I54I9 & hirsuta & Peru & peruvian runner \\
\hline II & ICG 3204 & fastigiata & China & valencia \\
\hline 12 & ICG 9987 & fastigiata & Bolivia & valencia \\
\hline 13 & ICG 10704 & fastigiata & China & valencia \\
\hline 14 & ICG II605 & fastigiata & Bolivia & valencia \\
\hline 15 & ICG I3430 & fastigiata & Chad & valencia \\
\hline 16 & ICG I442I & fastigiata & Nigeria & valencia \\
\hline 17 & ICGV 99004 & fastigiata & India & valencia \\
\hline 18 & ICG 6284 & fastigiata & USSR & - \\
\hline 19 & ICG 405 & fastigiata & Paraguay & - \\
\hline 20 & ICG 10074 & peruviana & Peru & - \\
\hline 21 & ICG I09II & peruviana & Peru & - \\
\hline 22 & ICG I705 & peruviana & Peru & - \\
\hline 23 & ICG 7898 & aequatoriana & Ecuador & - \\
\hline 24 & ICG I2553 & aequatoriana & Ecuador & - \\
\hline 25 & ICGI0384 & vulgaris & Nigeria & spanish \\
\hline 26 & ICG IIII75 & vulgaris & Bolivia & spanish \\
\hline 27 & ICG II505 & vulgaris & China & spanish \\
\hline 28 & ICG II5I5 & vulgaris & China & spanish \\
\hline 29 & ICG 12483 & vulgaris & Peru & spanish \\
\hline 30 & ICG I34I5 & vulgaris & Chad & spanish \\
\hline 31 & ICGV 9900I & vulgaris & India & spanish \\
\hline 32 & TMV 2 & vulgaris & India & spanish \\
\hline
\end{tabular}

When looking at SSR classes and motifs, the trinucleotide SSRs showed higher allele numbers (average 2.5 per locus) and PIC values (average 0.53 per marker) followed by dinucleotide (average alleles- 2.45 per locus; PIC valueaverage 0.45 per marker) and compound SSRs (average alleles- 2.35 per locus; PIC value- average 0.44 per marker). Among dinucleotide SSRs, GA/CT repeat motifs exhibited more informativeness (average alleles- 2.6 per locus and PIC value- average 0.50 per marker) as compared to GT/CA repeat motifs (average alleles- 2.0 per locus and PIC value- average 0.33 per marker). Ferguson and colleagues [8] as well as Moretzsohn and colleagues [9] observed higher informativeness of GA/CT repeat motifs. Therefore to develop more polymorphic markers for cultivated groundnut, we propose to isolate and develop the GA/CT repeat based SSR markers.

To understand the possible relationship between polymorphism of SSR markers with the repeat unit length of the corresponding SSRs, two scatter plots were made between repeat unit length and number of alleles detected (Fig. 1) and the PIC value calculated (Fig. 2). The scatter plot between number of alleles and repeat unit length shows the widest variation in number of alleles was between 13 and 20 repeats and a lower number of alleles found in the low number or very high number repeats. However it does not provide any conclusive relationships between the number of alleles and repeat unit length as indicated by Ferguson and colleagues [8] and Moretzsohn and colleagues [9] that loci with longer repeats are much more likely to be more variable. Indeed, among the polymorphic SSR markers, the IPAHM 147 marker containing highest number of repeat units (41) provided just 2 alleles while the IPAHM 103 markers with 20 repeat units long SSR revealed the highest number of alleles (5). This is possible as the majority of the polymorphic SSR markers detected 2 and 3 alleles in the present study.

The scatter plot between PIC value and repeat unit length indicates that the higher PIC values ( $>0.50)$ were between 13 and 20 repeats while lower PIC values were found in the low number $(<13)$ or very high number $(>20)$ repeats. It is noteworthy that the relationship appeared to be SSR class specific as it was more consistent for the com- 
Table 3: Polymorphism features of SSR markers developed

\begin{tabular}{|c|c|c|c|}
\hline S.No & Marker & No. of alleles & PIC \\
\hline I & IPAHM 23 & 2 & 0.40 \\
\hline 2 & IPAHM 73 & 3 & 0.62 \\
\hline 3 & IPAHM 82 & 2 & 0.34 \\
\hline 4 & IPAHM 92 & 2 & 0.12 \\
\hline 5 & IPAHM 93 & 3 & 0.60 \\
\hline 6 & IPAHMIO3 & 5 & 0.73 \\
\hline 7 & IPAHM I05 & 3 & 0.62 \\
\hline 8 & IPAHM 108 & 3 & 0.62 \\
\hline 9 & IPAHM I23 & 4 & 0.75 \\
\hline 10 & IPAHM I36 & 2 & 0.49 \\
\hline 11 & IPAHM I47 & 2 & 0.27 \\
\hline 12 & IPAHM I65 & 3 & 0.51 \\
\hline 13 & IPAHM 166 & 2 & 0.48 \\
\hline 14 & IPAHM I7I a & 3 & 0.55 \\
\hline 15 & IPAHM I7I c & 2 & 0.17 \\
\hline 16 & IPAHM I76 & 2 & 0.49 \\
\hline 17 & IPAHM I77 & 2 & 0.31 \\
\hline 18 & IPAHM 219 & 2 & 0.36 \\
\hline 19 & IPAHM 229 & 2 & 0.46 \\
\hline 20 & IPAHM 282 & 2 & 0.43 \\
\hline 21 & IPAHM 283 & 2 & 0.49 \\
\hline 22 & IPAHM 287 & 3 & 0.63 \\
\hline 23 & IPAHM 288 & 2 & 0.43 \\
\hline 24 & IPAHM 290 & 2 & 0.26 \\
\hline 25 & IPAHM 352 & 3 & 0.58 \\
\hline 26 & IPAHM 354 & 3 & 0.57 \\
\hline 27 & IPAHM 356 & 3 & 0.51 \\
\hline 28 & IPAHM 373 & 3 & 0.58 \\
\hline 29 & IPAHM 375 & 2 & 0.63 \\
\hline 30 & IPAHM 395 & 2 & 0.48 \\
\hline 31 & IPAHM 406 & 2 & 0.36 \\
\hline 32 & IPAHM 407 a & 2 & 0.30 \\
\hline 33 & IPAHM 429 & 2 & 0.35 \\
\hline 34 & IPAHM 45I & 2 & 0.13 \\
\hline 35 & IPAHM 455 & 2 & 0.31 \\
\hline 36 & IPAHM 468 & 2 & 0.32 \\
\hline 37 & IPAHM 475 & 3 & 0.67 \\
\hline 38 & IPAHM 524 & 2 & 0.48 \\
\hline 39 & IPAHM 53I & 2 & 0.48 \\
\hline 40 & IPAHM 540 & 2 & 0.25 \\
\hline 41 & IPAHM 569 & 2 & 0.38 \\
\hline 42 & IPAHM 659 & 4 & 0.69 \\
\hline 43 & IPAHM 684 & 2 & 0.46 \\
\hline 44 & IPAHM 689 & 2 & 0.50 \\
\hline 45 & IPAHM 716 & 3 & 0.70 \\
\hline 46 & IPAHM 718 & 2 & 0.12 \\
\hline
\end{tabular}

pound SSRs. As no other report, to the best of our knowledge, is available on relationship between PIC value and repeat unit length in groundnut, a direct comparison of the observed results could not be possible.

Based on our investigations on relationship of repeat unit length with number of alleles or PIC value, no consistent relationship between the number of repeat units and SSR polymorphism was observed. It has been reported earlier that the degree of polymorphism increases with the total

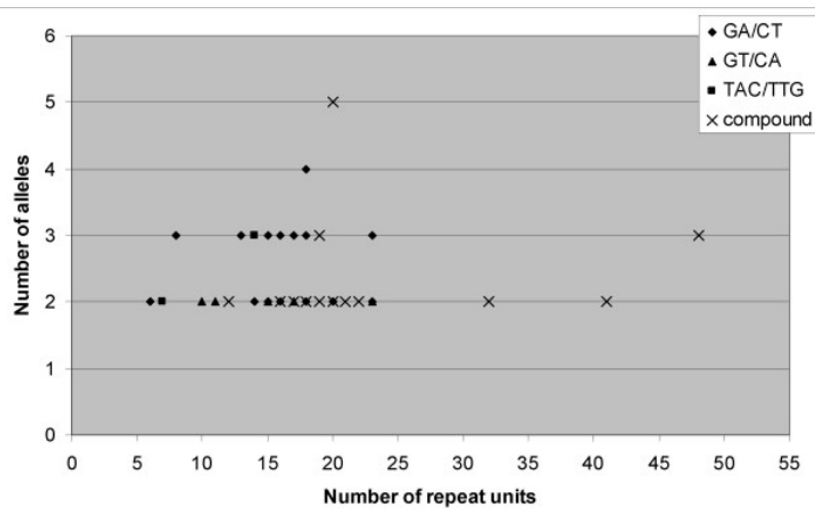

Figure I

Number of alleles per locus for SSR markers of different repeat units.

length of the repeat $[9,29,38,39]$, some other studies including in groundnut showed no relationship or weak correlation between SSR polymorphism and repeat unit length $[8,20,42,43]$.

\section{Diversity analysis and genetic relationships}

Based on the unique DNA fingerprint profiles of each accession of cultivated groundnut obtained by the polymorphic markers, a phenogram was constructed to understand the relationships among the cultivated groundnut germplasm surveyed. The dendrogram based on DICE similarity coefficient and constructed using the DARwin programme classified the germplasm in four main clusters A, B, C and D (Fig. 3). The cluster A contained 14 genotypes, the cluster $\mathrm{B}$ contained 8 genotypes while the other two clusters namely $\mathrm{C}$ and $\mathrm{D}$ contained 8 and 2 genotypes, respectively. Under each of these main clusters, genotypes were grouped further into sub clusters. For

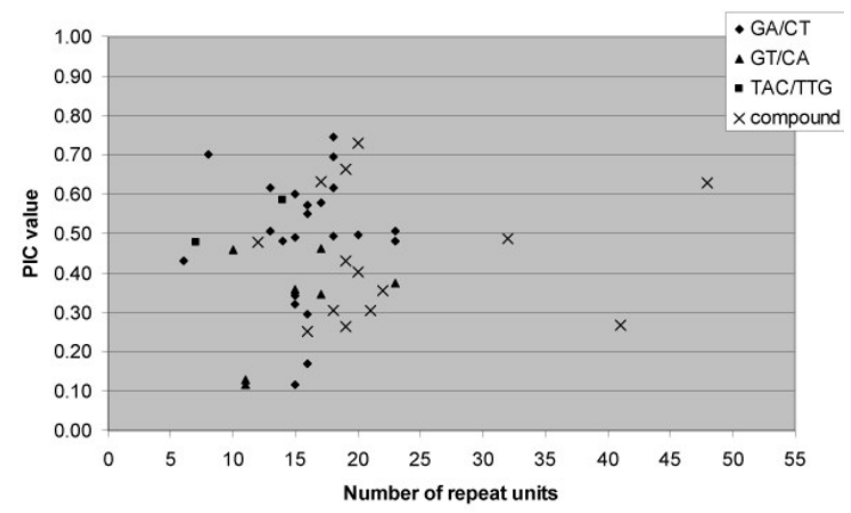

Figure 2

Relationships between PIC value of SSR markers and repeat unit length. 


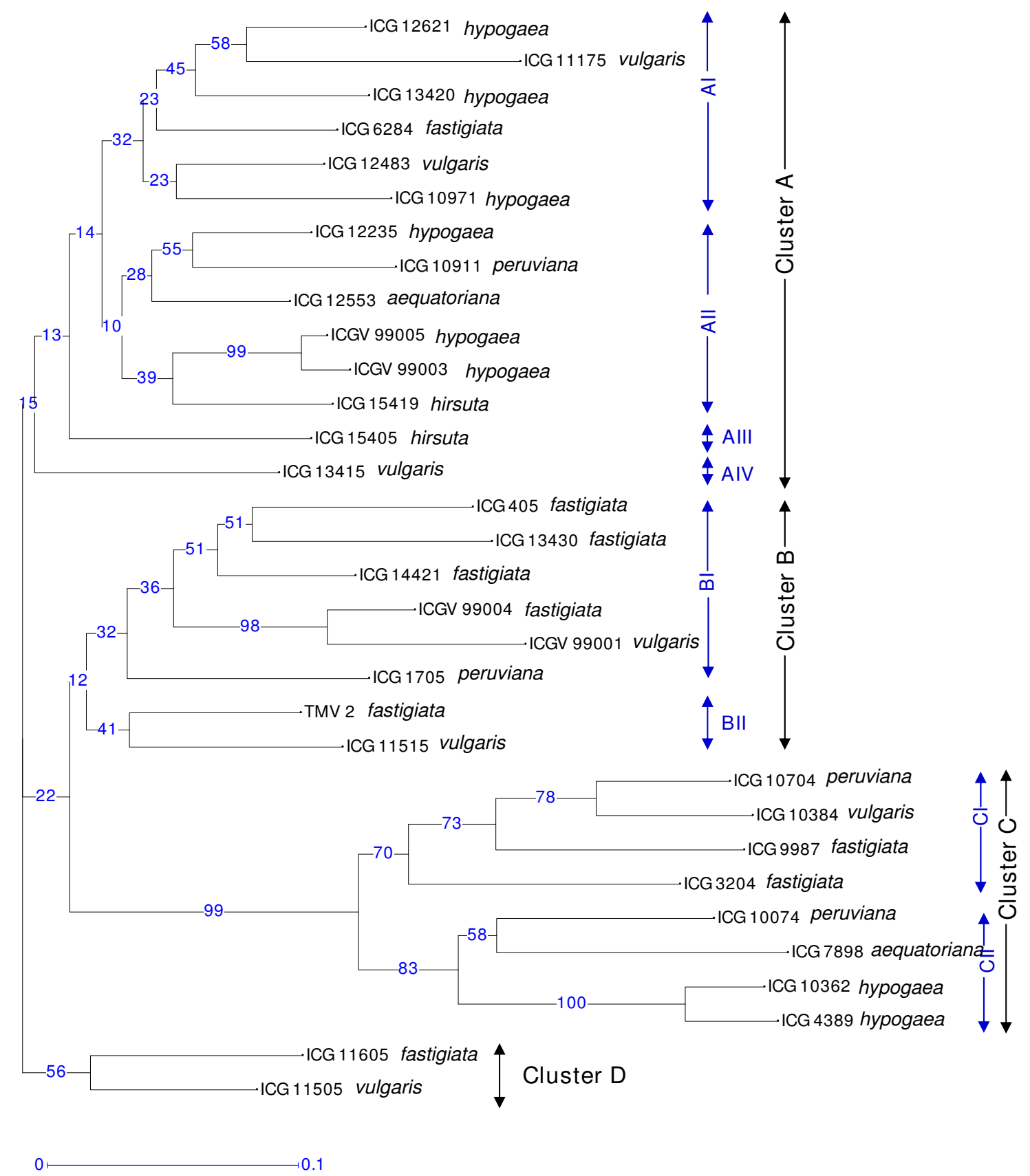

\section{Figure 3}

Dendrogram based on allele sharing genetic distances of 32 cultivated groundnut genotypes generated by the neighbor joining analysis method. The numbers on the branches indicate bootstrap values (expressed in percentages, based on 100 replications).

instance, the cluster A contained four subclusters (AI, AII, AIII and AIV) and the cluster B (BI, BII) and C (CI and CII) contained two subclusters each.

Majority of the genotypes ( 8 out of 10 ) representing subspecies hypogaea (6 hypogaea and 2 hirsuta genotypes) were found in the main cluster A. The genotypes belonging to fastigiata subspecies were grouped mainly under the main clusters B and C. The grouping of genotypes representing two subspecies in different clusters agrees with the classification of groundnut botanical varieties [44]. However, 
in an earlier study [45] genotypes representing the two subspecies were classified in only two groups.

The cluster B contained 4 (out of 10) genotypes belonging to variety fastigiata and three genotypes belonging to variety vulgaris. The cluster $\mathrm{C}$ also contained the genotypes from the fastigiata subspecies that includes 2 genotypes of variety fastigiata, 2 to variety peruviana and one each from varieties vulgaris and aequatoriana. The cluster $\mathrm{D}$ contained only 2 genotypes belonging to subspecies fastigiata. Majority of the nodes under the main clusters were supported by high bootstrap values.

It is important to note that positioning of botanical varieties aequatoriana and peruviana to the subspecies fastigiata or hypogaea has been debatable in the literature. For instance, in the past, based on morphological and physiological traits, two botanical varieties were classified under the subspecies fastigiata (that includes other varieties fastigiata and vulgaris) while AFLP markers suggested relationships of aequatoriana and peruviana to hypogaea rather than subspecies fastigiata [45]. The present study included only two aequatoriana and three peruviana genotypes, and they were grouped under all three major clusters (A, B and C). Nevertheless, like the observations of He and Prakash [45], four out of the five genotypes representing aequatoriana and peruviana subspecies showed closer relationships with the hypogaea genotypes (clusters AII and CII) while only one genotype of peruviana subspecies (ICG 1705) showed some proximity to subspecies fastigiata. The botanical variety peruviana, based on RAPD and ISSR marker data, was classified as an operational taxonomic unit in addition to four varieties i.e. fastigiata, vulgaris (both belonging to subspecies fastigiata), runner and bunch (both belonging to subspecies hypogaea) [46].

It is interesting to note that the two accessions with resistance to leaf rust (ICGV 99003 and ICGV 99005) were grouped together (AII) and similarly the other two accessions resistance to late leaf spot (ICGV 99001 and ICGV 99004 ) were grouped together (BI). It seems that genotypes resistant to leaf rust and late leaf spot shared the pedigree or have the same resource of resistance. However, three accessions resistance to early leaf spot (ICG 405, ICG 1705 and ICG 6284) were scattered in the dendrogram. The accession, TMV2, susceptible to all three diseases (leaf rust, late leaf spot and early leaf spot) was present under cluster $\mathrm{B}$. The dendrogram suggests the potential parental genotypes having higher genetic diversity for constructing the mapping population(s) for mapping the leaf rust, late leaf spot and early leaf spot. Even selection and utilization of diverse cultivars in breeding programmes is needed to enhance the diversity of breeding populations for selection gains in the future [47].

\section{Conclusion}

The results of this study highlight a reliable and efficient way of obtaining microsatellites markers from cultivated groundnut. It is desirable to isolate and characterize more DNA markers in cultivated groundnut for more productive genomic studies, such as genetic mapping, markerassisted selection, and gene discovery. Construction and sequencing of SSR enriched library yielded a total of 400 SSRs, however, primer pairs could be designed for only 170 SSRs of which 104 primer pairs showed the functionality. As a result, the present study contributes a new set of 104 SSR markers for cultivated groundnut. In order to assess the potential of newly developed markers for germplasm analysis, screening of these markers on 32 genotypes showed reasonable level of polymorphism. Newly developed markers detected on average 2.44 alleles per locus with an average PIC value 0.46 . The present study also provided some indications about nature and type of repeat class or length of SSRs on the polymorphism of corresponding SSR marker. Finally, the SSR markers, developed in this study would be very useful for germplasm analysis, population genetic structure and phylogenetic relationships.

\section{Methods \\ Plant material}

For constructing the SSR-enriched genomic libraries, the groundnut germplasm line TMV2, belonging to the Spanish botanical variety was used. While two genotypes (TMV2 and ICG 99001) were used for optimizing the PCR assays for newly developed SSR markers, a set of 32 genotypes were used for identifying the potential polymorphic markers for cultivated groundnut germplasm (Table 2). Of these 32 genotypes, 10 genotypes represent the subspecies hypogaea (2 to variety hirsuta and 8 to variety hypogaea) and the remaining 22 genotypes belong to subspecies fastigiata (10 to variety fastigiata, 7 to variety vulgaris, 3 to variety peruviana and 2 to variety aequatoriana).

\section{DNA extraction}

Total genomic DNA was isolated from unfurled leaves according to a modified CTAB-based procedure [48]. The quality of DNA was checked on $1 \%$ agarose gels and the DNA concentrations using spectrophotometer UV- 160A following the recommendations of manufacturer (Shimadzu Corporation, Japan).

\section{Construction of SSR-enriched library}

A modified protocol of Fischer and Bachmann [23] was used for constructing the SSR enriched library. Six micrograms of genomic DNA genomic were digested by blunt end - generating restriction endonuclease Rsal. After confirming digestion on agarose gel electrophoresis, the MluI adapter, consisting of a 21-mer (5'-CTCTTGCTTACGCGTGGACTA-3') and a phosphorylated 25-mer (5'-pTAGTC- 
CACGCGTAAGCAAGAGCACA-3') was ligated to the blunt termini of restriction fragments using $50 \mathrm{ng}$ adapter/ $\mu \mathrm{g}$ of genomic DNA. Ligation was performed for 2 hours at $37^{\circ} \mathrm{C}$ in order to allow the restriction digest to continue, hence preventing the DNA fragments from religating to one another. The ligation products were then separated on a 1\% TAE agarose gel and fragments size from 100-900 bp and 900-1500 bp cut from the gel and purified with GFX Gel Band Purification Kit (Amersham Biosciences, USA). The constructs were then heat denatured and hyribridised to biotinylated microsatellite oligonucleotides. The hybridizations were carried out using $75 \mu \mathrm{l}$ of $6 \times$ SSC and $150 \mathrm{nM}$ of each biotinylated oligo $(\mathrm{GT})_{15}$ and $(\mathrm{GA})_{15}$ overnight at $\mathrm{T}_{\mathrm{hyb}}=\mathrm{T}_{\mathrm{m}}-5^{\circ} \mathrm{C}$. The hybrids were subsequently bound to streptavidin - coated magnetic beads (Dynabeads M -280 Streptavidin- Dynal, Norway). In order to capture the target sequences, the beads were incubated either at room temperature for $15 \mathrm{~min}$ for the 100-900 bp fragments or at $43^{\circ} \mathrm{C}$ for one hour for the 900-1500 bp fragments. Non-hybridizing genomic DNA was subsequently removed through a series of washes; twice in $2 \times \mathrm{SSC} ; 0.1 \%$ SDS ( 5 mins each, at $25^{\circ} \mathrm{C}$ ), twice in $1 \times \operatorname{SSC}\left(5 \mathrm{mins}\right.$ each, at $\left.25^{\circ} \mathrm{C}\right)$ and finally twice in $1 \times \mathrm{SSC}$ at $\mathrm{T}_{\text {hyb }}$ for 2 and 5 mins respectively. The bound DNA was eluted as single stranded fragments in TE preheated to $95^{\circ} \mathrm{C}$.

The hybridized DNA fragments served as a template for PCR using the 21-mer oligonucleotide as the primer (30 cycles with $56^{\circ} \mathrm{C}$ annealing temperature). Following PCR, like samples were combined and purified using the GFX column purification Kit (Amersham Biosciences, USA). The purified PCR products were then digested with MluI to obtain vector-compatible, sticky ended fragments by incubation at $37^{\circ} \mathrm{C}$ overnight. The restriction fragments were purified using a MicroSpin ${ }^{\mathrm{TM}}$ column (Amersham Biosciences, USA) prior to ligation into a modified pUC19 vector (pJV1) (Edwards et al., 1996 [11]) which had been linearized with BssHII and dephosphorylated. The ligated vector fragments were transformed into competent E. coli DH5 $\alpha$ cells (Invitrogen, USA), plated on LB agar containing ampicillin $(100 \mu \mathrm{g} / \mathrm{ml})$. To allow for blue-white selection, the plates were spread with 5bromo-4-chloro-3-indolyl- $\beta$-D-galactopyranoside (X-gal; $80 \mu \mathrm{g} / \mathrm{ml}$ ) plus isopropyl $\beta$-D-thiogalactopyranoside (IPTG; $80 \mu \mathrm{g} / \mathrm{ml}$ ). White colonies were picked and plated in a grid on LB containing ampicillin, prior to making colony lifts with Nylon Membranes, positively charged, following the recommendation of manufacturer (Amersham Biosciences, USA). Hybridization was carried out at $42{ }^{\circ} \mathrm{C}$ overnight using digoxigenin-labelled probes containing the SSR motifs being searched (Roche, Germany).

\section{Sequencing of SSR-positive clones}

The SSR positive clones identified after hybridization were grown overnight in $3 \mathrm{ml} \mathrm{LB}$ broth with $100 \mu \mathrm{g} / \mathrm{mL}$ ampicillin. Plasmid DNA was extracted using GFX ${ }^{\mathrm{TM}}$ Micro Plasmid Prep Kit (Amersham Biosciences, USA). Subsequently, the plasmid DNA was sequenced using M13 Forward 24-mer Sequencing Primer following the dideoxynucleotide chain termination method on ABI 3700 sequencer. Base calling was carried out using Phred [49]. Sequence data were quality trimmed using the sliding windows of $50 \mathrm{bp}$ with a minimal average Phred score of 20 .

\section{SSR identification and primer designing}

The sequencing data were analysed using the ClustalW programme in order to determine the rate of redundancy in the library. Non-redundant sequences were analysed with Tandem Repeat Finder software [50]. The SSR containing sequences were subsequently used for primer design using Primer3 programme. Primers were designed from within the regions flanking the repeat motifs; for dinucleotides the repeat motifs selected were greater than 14 bp in length, trinucleotides greater than 15 bp and tetranucleotides greater than $16 \mathrm{bp}$.

\section{Amplification and visualization of microsatellite loci}

PCR reactions for all the primer pairs were performed in 5 $\mu \mathrm{l}$ reaction volume following three touch down profiles i.e. $65-55^{\circ} \mathrm{C}$ ( 89 markers), $60-55^{\circ} \mathrm{C}$ (14 markers) and $55-45^{\circ} \mathrm{C}$ ( 1 marker). The PCR was performed on $5 \mathrm{ng}$ of genomic DNA with varying amount of primer pairs, $\mathrm{Mg}^{2+}$, dNTPs and Taq DNA polymerase. Details on these reaction components for each primer pair (marker), that yielded PCR amplicon, are given in Additional file 1. Touch down amplification programs included $94^{\circ} \mathrm{C}$ for 2 min, 30 cycles of $94^{\circ} \mathrm{C}$ for $45 \mathrm{sec}$, annealing temperature $\left(65-55^{\circ} \mathrm{C} / 60-55^{\circ} / 55-45^{\circ} \mathrm{C}\right)$ for $60 \mathrm{sec}, 72^{\circ} \mathrm{C}$ for $60 \mathrm{sec}$ and a final extension of $10 \mathrm{~min}$ at $72^{\circ} \mathrm{C}$.

The PCR products were separated on a non- denaturing $6 \%$ polyacrylamide gel at $250 \mathrm{~V}$ for 2.5 to 3 hours in $1 \times$ TBE buffer and visualized by silver staining, modified from Kolodny [51]. The presence or absence of amplicons in the genotypes examined was scored as 1 or 0 , respectively.

\section{Statistical analysis}

The polymorphism information content (PIC) of each microsatellite locus was determined as described by Weir [52]:

$$
\mathrm{PIC}=1-\Sigma P_{\mathrm{i}}^{2}
$$

where $P_{\mathrm{i}}$ is the frequency of the $i$ th allele in the genotypes examined. 
Allelic data obtained in $0-1$ fashion for all alleles at microsatellite loci amplified were used for computing the inter-individual genetic dissimilarity following simple matching coefficient by using DARwin v 5.0.153 programme [53]. The dissimilarity matrix thus generated was further used to generate UPGMA (Unweighted Pair Group Method with Arithmetic mean) dendrogram following neighbour-joining (NJ) by using the DARwin programme.

\section{Authors' contributions}

LMC and ESM executed majority of the research work, VDQ, TDL and RKV analyzed the data. JHC, ESM and RKV were involved in designing and planning the work and interpreting the results. RKV drafted and edited the manuscript critically with help of LMC. All authors read and approved the final manuscript.

\section{Additional material}

\section{Additional file 1}

Features and polymorphism status of new set of SSR markers developed. The data provided represent the details of the new set of SSR markers e.g. marker name, Genbank accession IDs, primer sequences, PCR conditions and amplification status.

Click here for file

[http://www.biomedcentral.com/content/supplementary/14712229-8-55-S1.doc]

\section{Acknowledgements}

Authors gratefully acknowledge Mr. A. Gafoor for technical assistance and $\mathrm{Dr}$ H. D. Upadhyaya for providing the germplasm analysed in this study.

Thanks are due to Asian Development Bank and Indian Council of Agriculture Research (National Fund, India) for sponsoring the research projects 'Rapid crop improvement for poor farmers in the semi-arid tropics of Asia' and 'Gene-based genetic maps and molecular markers for biotic and abiotic stress tolerance in cultivated groundnut', respectively that made this study possible.

\section{References}

I. Dwivedi SL, Crouch JH: Proceedings of a Workshop for the Asian Development Bank supported project on molecular breeding of sorghum, groundnut and chickpea. ICRISAT 2003:28-43.

2. Weiss EA: Oilseed Crops London, UK: Longman; 1983:660.

3. Savage GP, Keenan J: The composition and nutritive value of groundnut kernels. In The groundnut crop: A scientific basis for improvement Edited by: Smart J. London, UK: Chapman and Hall; 1994:173-213.

4. Stalker HT, Moss JP: Speciation, cytogenetics and utilization of Arachis species. Adv Agron 1987, 41:1-39.

5. Young ND, Weeden NF, Kochert G: Genome mapping in legumes (Fam. Fabaceae). In Genome Mapping in Plants Edited by: Paterson AH. Austin, USA: Landes Company; 1996:21 I-227.

6. Singh AK, Smartt J, Simpson CE, Raina SN: Genetic variation via molecular polymorphism in groundnut, Arachis hypogaea $\mathbf{L}$. Genet Resour Crop Evol 1998, 45: I 19-126.

7. Gupta PK, Varshney RK: The development and use of microsatellite markers for genetic analysis and plant breeding with emphasis on bread wheat. Euphytica 2000, I I3:163-185.

8. Ferguson ME, Burow MD, Schultz SR, Bramel PJ, Paterson AH, Kresovich S, Mitchell S: Microsatellite identification and characteri- zation in peanut (A. hypogaea L.). Theor Appl Genet 2004, 108: 1064-1070.

9. Moretzsohn MC, Leoi L, Proite K, Guimaraes PM, Leal-Bertioli SCM, Gimanes MA, Martin WS, Valls JFM, Grattapaglia D, Bertioli D: A microsatellite - based, gene-rich linkage map for the AA genome of Arachis (Fabaceae). Theor Appl Genet 2005, I I I:1060-107|.

10. Mace ES, Varshney RK, Mahalakshmi V, Seetha K, Gafoor A, Leeladevi $\mathrm{Y}$, Crouch JH: In silico development of simple sequence repeat markers within the aeschynomenoid/dalbergoid and genistoid clades of the Leguminosae family and their transferability to Arachis hypogaea, groundnut. Plant Sci 2007, 1 74:5 I-60.

II. Edwards KJ, Barker JHA, Daly A, Jones C, Karp A: Microsatellite libraries enriched for several microsatellite sequences in plants. BioTechniques 1996, 20:759-760.

12. Karagyozov L, Kalcheva ID, Chapman VM: Construction of random small-insert genomic libraries highly enriched for simple sequence repeats. Nucl Acids Res 1993, 21:3911-3912.

13. Kijas JMH, Fowler JCS, Garbett CA, Thomas MR: Enrichment of microsatellites from the citrus genome using biotinylated oligonucleotide sequences bound to streptavidin-coated magnetic particles. BioTechniques 1994, 16:656-662.

14. Ito T, Smith CL, Cantor CR: Sequence-specific DNA purification by triplex affinity capture. Proc Natl Acad Sci USA 1992, 89:495-498.

15. Varshney RK, Hoisington DA, Upadhyaya HD, Gaur PM, Nigam SN, Saxena K, Vadez V, Sethy NK, Bhatia S, Aruna R, Gowda MVC, Singh NK: Molecular genetics and breeding of grain legume crops for the semi-arid tropics. In Genomic Assisted Crop Improvement Genomics Applications in Crops Volume II. Edited by: Varshney RK, Tuberosa R. Dordrecht, The Netherlands: Springer; 2007:207-242.

16. Hopkins MS, Casa AM, Wang T, Mitchell SE, Dean RE, Kochert GD, Kresovich S: Discovery and characterization of polymorphic simple sequence repeats (SSRs). Crop Sci 1999, 39:1243-1247.

17. Palmieri DA, Hoshino AA, Bravo JP, Lopes CR, Gimenes MA: Isolation and characterization of microsatellite loci from the forage species Arachis pintoi (Genus Arachis). Mol Ecol Notes 2002 , 2:55I-553.

18. Gimenes MA, Hosino AA, Barbosa AVG, Palmieri DA, Lopes CR Characterization and trasferability of microsatellite markers of cultivated peanut (Arachis hypogaea). BMC Plant Biol 2007, 7:9.

19. He G, Prakash CS: Identification of polymorphic DNA markers in cultivated peanut (Arachis hypogaea. L.). Euphytica 1997, 97:143-149.

20. He G, Meng R, Newman M, Gao GM, Pittman RN, Prakash CS: Microsetellites as DNA markers in cultivated peanut (Arachis hypogaea L.). BMC Plant Biology 2003, 3:3

21. Moretzsohn MC, Hopkins MS, Mitchell SE, Kresovich S, Valls JFM, Ferreira ME: Genetic diversity of peanut (Arachis hypogaea L.) and its wild relatives based on the analysis of hypervaraible regions of the genome. BMC Plant Biology 2004, 4: II.

22. Luo M, Dang P, Guo BZ, He G, Holbrook CC, Bausher MG, Lee RD Generation of expressed sequence tag (ESTs) for gene discovery and marker development in cultivated peanut. Crop Sci 2005, 45:346-353.

23. Fischer $\mathrm{D}$, Bachmann $\mathrm{K}$ : Microsatelite enrichment in organisms with large genomes (Allium cepa L.). Biotechniques 1998 , 24(5):796-800, 802.

24. Wang CT, Yang XD, Chen DX, Yu SL, Liu GZ, Tang YY, Xu JZ: Isolation of simple sequence repeats from groundnut. Elect Jour Biotechnol 2007, 10:473-480.

25. Rallo P, Dorado G, Martin A: Development of simple sequence repeats (SSRs) in olive tree (Olea europaea L.). Theor Appl Genet 2000, 101:984-989.

26. Fisher PJ, Richardson TE, Gardner RC: Characteristics of singleand multi-copy microsatellites from Pinus radiata. Theor Appl Genet 1998, 96:969-979.

27. Koblizkova A, Dolezel J, Macas J: Subtraction with 3 ' modified oligonucleotides eliminates amplification artifacts in DNA libraries enriched for microsatellites. BioTechniques 1998, 25:32-38.

28. Becher SA, Steinmetz K, Weising K, Boury S, Peltier D, Renou JP, Kahl G, Wolff K: Microsatellites for cultivar identification in Pelargonium. Theor Appl Genet 2000, 10 I:643-651. 
29. Weber JL: Informativeness of human $(\mathbf{C C}-\mathbf{d A})_{\mathbf{n}}(\mathbf{d G}-\mathbf{d T})_{\mathbf{n}}$ polymorphisms. Genomics 1990, 7:524-530.

30. Condit R, Hubbel SP: Abundance and DNA sequence of twobase repeat regions in tropical tree genomes. Genome 199I, 34(I):66-7I.

31. Largercrantz $U$, Ellegren $H$, Andersson $L$ : The abundance of various polymorphic microsatellite motifs differs between plants and vertebrates. Nucleic Acids Res 1993, 2 I: I I I I-I I I 5.

32. Morgante M, Olivieri AM: PCR-amplified microsatellites as markers in plant genetics. Plant J 1993, 3(I): 175- 182

33. Wang Z, Weber JL, Zhong G, Tanksley SD: Survey of plant short tandem repeats. Theor Appl Genet 1994, 88: I-6.

34. Powell W, Machray GC, Provan J: Polymorphism revealed by simple sequence repeats. Trends Plant Sci 1996, I:2 15-222.

35. De Wiel CV, Arens P, Vosman B: Microsatellite retrieval in lettuce (Lactuca sativa L.). Genome 1998, 42: I39-I50.

36. Butcher PA, Decroocq S, Gray Y, Moran GF: Development, inheritance and cross-species amplification of microsatellite markers from Acacia mangium. Theor Appl Genet 2000, I0I: I282-1290.

37. Akkaya MS, Bhagwat AA, Cregan PB: Length polymorphism of simple sequence repeat DNA in soybean. Genetics 1992, 132:1131-1139.

38. Hüttel B, Winter P, Weising K, Choumane W, Weigand F, Kahl G: Sequence-tagged microsatellite-site markers for chickpea (Cicer arietinum L.). Genome 1999, 42:210-217.

39. Burstin J, Deniot G, Potier J, Weinachter C, Aubert G, Baranger A: Microsatellite polymorphism in Pisum sativum. Plant Breed 200I, I 20:3|I-3I7.

40. He G, Meng R, Gao H, Guo B, Newman M, Pittman RN, Prakash CS: Simple sequence repeat markers for botanical varieties of cultivated peanut (Arachis hypogaea. L.). Euphytica 2005, 142:131-136.

4I. Varshney RK, Graner A, Sorrells ME: Genic microsatellite markers in plants: features and applications. Trends Biotechnol 2005, 23(I):48-55.

42. Love J, Knight A, Mc Aleer M, Todd J: Towards construction of a high-resolution map of the mouse genome using PCR analyzed microsatellites. Nucleic Acids Res 1990, I 8:4I23-4130.

43. Yu K, Park S, Poysa V: Abundance and variation of microsatellite DNA sequence in Beans (Phaseolus and Vigna). Genome 1999, 42:27-34.

44. Krapovickas A, Gregory WC: Taxonomia del genero Arachis (Leguminosae). Bonplandia 1994, 8: I-I86.

45. He G, Prakash C: Evaluation of genetic relationships among botanical varieties of cultivated peanut (Arachis hypogaea L.) using AFLP markers. Genet Resour Crop Evol 200 I, 48:347-353

46. Raina SN, Rani V, Kojima T, Ogihara Y, Singh KP, Devarumath RM: RAPD and ISSR fingerprints as useful genetic markers for analysis of genetic diversity, varietal identification, and phylogenetic relationships in peanut (Arachis hypogaea) cultivars and wild species. Genome 200I, 44:763-772.

47. Krishna GK, Zhang J, Burow M, Pittman RN, Delikostadinov SG, Lu Y, Puppala N: Genetic diversity analysis in Valencia peanut (Arachis hypogaea L.) using microsatellite markers. Cell Mol Biol Lett 2004, 9:685-697.

48. Mace ES, Buhariwalla HK, Crouch JH: A high-throughput DNA extraction protocol for tropical molecular breeding programs. Plant Mol Biol Rep 2003, 21:459a-459h.

49. Ewing B, Hillier L, WendI MC, Green P: Base-calling of automated sequencer traces using phred. I. Accuracy assessment. Genome Res 1998, 8:175-185.

50. Benson G: Tandem Repeats Finder: a program to analyse DNA sequence. Nucleic Acid Res 1999, 27:573-580 [http://tan dem.bu.edu/trf/trf.html].

51. Kolodny GM: An improved method for increasing the resolution and sensitivity of silver staining of nucleic acid bands in polyacrylamide gels. Anal Biochem 1984, I38(I):66-67.

52. Weir BS: Genetic data analysis. Methods for discrete genetic data. Sunderland Massachusetts: Sinauer Associates; 1990:125.

53. Perrier X, Jacquemond-Collet JP: DARwin software. 2006 [http:// darwin.cirad.fr/darwin/]
Publish with Biomed Central and every scientist can read your work free of charge

"BioMed Central will be the most significant development for disseminating the results of biomedical research in our lifetime. "

Sir Paul Nurse, Cancer Research UK

Your research papers will be:

- available free of charge to the entire biomedical community

- peer reviewed and published immediately upon acceptance

- cited in PubMed and archived on PubMed Central

- yours - you keep the copyright
BioMedcentral 